\title{
PENGARUH SENAM DIABETES TERHADAP PENURUNAN KADAR GULA DARAH PADA PASIEN DIABETES MELLITUS
}

\author{
Febri Fitriani ${ }^{1}$, RA Fadilla ${ }^{2}$ \\ Program Studi Sarjana Keperawatan STIKES Mitra Adiguna Palembang \\ Komplek Kenten Permai Blok J No 9-12 Bukit Sangkal Palembang 30114 \\ Email: febrifitriani857@gmail.com
}

\begin{abstract}
Abstrak
Diabetes Mellitus disebabkan karena defisiensi absolut atau relatif yang disebabkan metabolisme karbohidrat, lemak, protein. Diabetes mellitus merupakan salah satu penyakit kronik yang memerlukan waktu perawatan lama, pembiayaan perawatan yang sangat mahal, selain itu prevalensi diabetes mellitus juga terus meningkat. Senam diabetes adalah latihan fisik aerobic bagi penderita diabetes dengan serangkaian gerakan yang dipilih secara sengaja dengan cara mengikuti irama musik, kontinuitas dan durasi tertentu untuk mencapai tujuan tertentu. Tujuan penelitian ini untuk mengetahui kadar gula darah sebelum dan setelah dilakukan senam diabetes. Penelitian ini menggunakan rancangan penelitian one group pre test and post test design. Sampel dalam penelitian ini berjumlah 30 responden pasien Diabetes Mellitus tipe II yang mampu mengikuti senam. Sampel diambil dengan menggunakan metode purposive sampling. Hasil penelitian statistic dengan menggunakan uji Paired Sample T Test diperoleh nilai $\rho$ 0,000 yang berarti $\rho$ value $<0,05$ menunjukkan bahwa adanya pengaruh senam diabetes terhadap penurunan kadar gula darah pada pasien Diabetes Mellitus tipe II di Klinik Symponi Danarieva Medika Palembang. Saran dalam penelitian ini diharapkan dapat menjadi masukan dan pertimbangan untuk mengadakan evaluasi secara rutin kadar gula darah sebelum dan setelah senam diabetes khususnya pada pasien Diabetes Mellitus tipe II di Klinik Symponi Danarieva Medika Palembang agar dapat terkontrol.
\end{abstract}

\section{Kata kunci ：Diabetes Mellitus, Senam Diabetes}

\begin{abstract}
Emergency Department (IGD) is a very important entry point for health care for patients who need urgent treatment and care both emergency and emergency. Triage is important in treating and conducting initial assessments of patients in the ED. Emergency patients must be treated with medical response time $<5$ minutes. The purpose of this study was to determine the relationship between the level of nurses' knowledge about response time in determining triage in the Emergency Room at Pusri Hospital and Palembang AR-Rasyid Islamic Hospital. This research uses analytic method with cross sectional approach. The sample in this study amounted to 30 nurse respondents in the Emergency Room of the Pusri Hospital and Palembang AR-Rasyid Islamic Hospital. Samples were taken using a purposive sampling method. The results of the study used the Chi-Square Test with a significance level of 95\% ( $\alpha \leq 0.05)$ obtained $\rho$ value 0.001 which means $\rho$ value $\leq \alpha(0.05)$. Thus that there is a relationship between the level of nurse knowledge about response time in determining triage. Suggestions in this study are expected to conduct routine evaluations of nurses' knowledge about response time in handling patients in the Emergency Room so that they can improve the quality of service
\end{abstract}

Key Word : Response time, Triase

Jurnal Kesehatan dan Pembangunan, Vol. 10, No. 19, Januari 2020 


\section{PENDAHULUAN}

Sistem endokrin mengatur dan mempertahankan fungsi tubuh, jika terjadi gangguan endokrin akan menimbulkan masalah yang komplek terutama metabolisme fungsi tubuh terganggu. Salah satu gangguan endokrin adalah Diabetes Mellitus yang disebabkan karena defisiensi absolut atau relatif yang disebabkan metabolisme karbohidrat, lemak, protein (Maulana, 2008).

Kelenjar endokrin atau kelenjar buntu adalah kelenjar yang mengirimkan hasil sekresinya langsung ke dalam darah yang beredar dalam jaringan kelenjar tanpa melewati duktus atau saluran dan hasil sekresinya disebut hormon. Jika kelenjar endokrin mengalami kelainan fungsi, maka kadar hormon di dalam darah bisa menjadi tinggi atau rendah, sehingga mengganggu fungsi tubuh untuk mengendalikan fungsi endokrin, maka pelepasan setiap hormon harus diatur dalam batas-batas yang tepat (Maulana, 2008).

Diabetes mellitus merupakan salah satu penyakit kronik yang memerlukan waktu perawatan lama, pembiayaan perawatan yang sangat mahal, selain itu prevalensi diabetes mellitus juga terus meningkat. Perubahan gaya hidup seperti makan, berkurangnya aktivitas fisik dan obesitas dianggap sebagai faktor-faktor penyebab terpenting sehingga tidak terkontrolnya kadar gula darah yang membuat kita terkena. Jika tidak waspada, bukan hanya kita tetapi anak-anak kita juga bisa menjadi korbannya. Oleh karena itu diabetes mellitus dapat saja timbul pada orang tanpa riwayat diabetes mellitus dalam keluarga, dimana proses terjadinya penyakit memakan waktu bertahun-tahun dan sebagaian besar berlangsung tanpa gejala (Sanjaya, 2014).

Olahraga yang dianjurkan salah satunya yaitu latihan fisik aerobic, karena kebutuhan oksigen selama kerja harus terus terpenuhi oleh tubuh, sehingga sistem transport oksigen, yang terutama terdiri dari paru-paru, jantung dan pembuluh darah diharuskan bekerja intensif secara terus menerus organ-organ yang penting yang bekerja dan pengeluaran energi berlangsung cukup efektif (Santoso dalam Nugraha et al., 2016)

Senam diabetes adalah latihan fisik aerobic bagi penderita diabetes dengan serangkaian gerakan yang dipilih secara sengaja dengan cara mengikuti irama music sehingga melahirkan ketentuan ritmis, kontinuitas dan durasi tertentu untuk mencapai tujuan tertentu. Senam diabetes akan lebih baik dilakukan dalam waktu 45 menit dengan frekuensi 3-5 kali perminggu (Ashadi dalam Nugraha et al.,2016).

Pada saat berolahraga, otot berkontraksi dan kemudian mengalami relaksasi. Gula akan dipakai atau dibakar untuk energi. Untuk kebutuhan energi, gula akan dipindahkan dari darah ke otot selama dan setelah berolahraga. Dengan demikian, gula darah akan turun. Di samping itu, olahraga membuat insulin menjadi lebih sensitif. Insulin akan bekerja dengan lebih baik untuk membuka pintu masuk bagi gula kedalam sel (Tandra, 2017).

Salah satu klinik di Palembang yang memiliki klub senam diabetes adalah Klinik Symponi Danarieva Medika Palembang. Berdasarkan data awal yang didapat dari Klinik Symponi Danarieva 
Medika Palembang pada tahun 2016 sebanyak 23 peserta, pada tahun 2017 sebanyak 36 peserta, pada tahun 2018 sebanyak 39 peserta dan pada bulan Januari-Februari 2019 didapatkan data dengan penyakit Diabetes Mellitus sebanyak 40 peserta.

Berdasarkan uraian diatas, maka peneliti tertarik untuk melakukan penelitian dengan judul "Pengaruh Senam Diabetes Terhadap Penurunan Kadar Gula Darah Pada Pasien Diabetes Mellitus di Klinik Symponi Danarieva Medika Palembang Tahun 2019".

\section{METODE PENELITIAN}

Jenis Penelitian

Dalam penelitian ini, kelompok sampel hanya terdiri dalam satu kelompok perlakuan yang kemudian diberikan pretest menggunakan lembar observasi pengukuran kadar gula darah dan setelah perlakuan (dilakukan senam diabetes sebanyak 3x/minggu dan selama \pm 45 menit) dilakukan posttest dengan lembar observasi pengukuran kadar gula darah seminggu setelah 3 kali senam.

\section{Waktu dan Tempat Penelitian}

Penelitian ini dilaksanakan selama 7 hari pada tanggal 29 Maret- 04 April 2019 di Klinik Symponi Danarieva Medika Palembang.

\section{Target/Subjek Penelitian}

Pengambilan sampel pada penelitian ini dilakukan dengan cara non probability sampling menggunakan metode purposive sampling yaitu pengambilan sampel didasarkan pada suatu pertimbangan tertentu yang dibuat oleh peneliti sendiri berdasarkan cirri atau sifat- sifat populasi yang sudah diketahui sebelumnya (Notoatmodjo, 2012).

Kriteria Inklusi yaitu : Pasien Diabetes Mellitus tipe II, mampu mengikuti senam diabetes 3 kali dalam seminggu, tidak memiliki gangguan jiwa, dan bersedia menjadi responden penelitian.

\section{Prosedur}

Jenis penelitian ini pre-eksperimen dengan menggunakan rancangan one group pretest-posttest.

Pengumpulan data melalui dokumen seperti arsip data dari Klinik Symponi Danarieva Medika Palembang. Peneliti menjelaskan kepada koresponden yang memenuhi kriteria inklusi tentang penelitian yang akan dilakukan, menanyakan kepada koresponden apakah bersedia menjadi responden dalam penelitian atau tidak. Serta membagikan lembar persetujuan untuk menjadi responden dalam penelitian (Informed Consent), Peneliti membagikan kuisioner kepada responden dan responden melakukan pengisian kuisioner. Kuisioner diambil kembali 30 menit kemudian, melakukan observasi terhadap kadar gula darah pada pasien Diabetes Mellitus tipe II sebelum dan sesudah mengikuti senam sebanyak 3 kali dalam seminggu di Klinik Symponi Danarieva Medika Palembang.

\section{Data, Instrumen, dan Teknik Pengumpulan Data}

Penelitian ini menggunakan instrument penelitian lembar observasi kadar gula darah sebelum melakukan senam dan kadar gula darah setelah melakukan senam sebanyak 3 kali dalam seminggu.

Data dimasukan dalam master tabel dan pengolahan data dilakukan melalui 
analisis statistik dengan menggunakan komputer.

\section{Teknik Analisa Data}

Analisis univariat dilakukan terhadap variabel dari hasil penelitian yaitu variabel dependen (kadar gula darah) yang dianalisis dengan menggunakan tabel distribusi frekuensi.

Pada penelitian ini, analisis bivariat dilakukan dengan terlebih dahulu melakukan uji normalitas data primer menggunakan uji one sample kolmogorovsmirnov test dengan ketentuan jika $\rho$ value $\geq(0,05)$ berarti data terdistribusi normal dan jika $\rho$ value $<(0,05)$ berarti data tidak terdistribusi normal.

Selanjutnya untuk uji pengaruh menggunakan uji statistic Paired Samples $T$ Test dengan tingkat kemaknaan $\alpha 0,05$ bila data terdistribusi normal

Dalam melakukan penelitian, peneliti memperhatikan masalah-masalah etika penelitian yang meliputi: informed consent, anonimity, confidentiality.

\section{HASIL DAN PEMBAHASAN}

Analisis Univariat

Tabel 1. Distribusi Frekuensi Responden Berdasarkan Jenis Kelamin di Klinik Symponi Danarieva Medika Palembang

\begin{tabular}{lcc}
\hline Jenis Kelamin & $(\mathbf{n})$ & $(\boldsymbol{\%})$ \\
\hline Laki-laki & 13 & $43,3 \%$ \\
Perempuan & 17 & $56,7 \%$ \\
\hline Total & 30 & $100,0 \%$
\end{tabular}

Sumber : Data primer, 2019

Berdasarkan tabel 1. terlihat bahwa subjek penderita DM tipe II pada penelitian dengan jenis kelamin perempuan merupakan proporsi sampel paling tinggi, yaitu sebanyak 17 responden $(56,7 \%)$ dari seluruh sampel penelitian.
Adapun proporsi sampel dengan jenis kelamin laki-laki adalah sebanyak 13 responden $(43,3 \%)$.

Perempuan lebih berpeluang untuk terjadi DM dibandingkan laki laki dengan alasan faktor hormonal dan metabolisme, bahwa perempuan mengalami siklus bulanan dan menopouse yang berkontribusi membuat distribusi peningkatan jumlah lemak tubuh menjadi sangat mudah terakumulasi akibat proses tersebut sehingga perempuan lebih berisiko terkena penyakit DM tipe dua (Irawan, 2010).

Data tersebut sesuai dengan penelitian Indriyani (2007) yang menyatakan bahwa diabetes melitus pada usia 40 - 70 tahun lebih banyak terjadi pada perempuan, Sedangkan pada laki-laki lebih banyak terjadi pada usia yang lebih muda. Hal ini dipicu oleh fluktuasi hormonal saat sindroma siklus bulanan (pre-menstrual syndrome) dan pascamenopause pada perempuan yang membuat distribusi lemak menjadi mudah terakumulasi dalam tubuh sehingga indeks massa tubuh (IMT) meningkat dengan persentase lemak lebih tinggi yakni berkisar $20-25 \%$ dari berat badan total dan kadar LDL yang tinggi dibandingkan dengan laki-laki yang umumnya memiliki jumlah lemak berkisar 15-20\% dari berat badan total. Kondisi ini mengakibatkan penurunan sensitifitas terhadap kerja insulin pada otot dan hati.Akibatnya perempuan memiliki faktor risiko terjadinya DM 3-7 kali lebih tinggi.

Tabel 2. Distribusi Frekuensi Kadar Gula Darah Sebelum Dilakukan Senam Diabetes di Klinik Symponi Danarieva Medika Palembang

\begin{tabular}{|c|c|c|}
\hline Kadar Gula Darah & (n) & $(\%)$ \\
\hline Normal $(<200 \mathrm{mg} / \mathrm{dL})$ & 9 & $30,0 \%$ \\
\hline Tinggi $\quad(>200 \mathrm{mg} / \mathrm{dL})$ & 21 & $70,0 \%$ \\
\hline
\end{tabular}




\begin{abstract}
Total
30

$100,0 \%$

Sumber : Data primer, 2019

Berdasarkan tabel 2 diatas menunjukkan bahwa sebelum dilakukan senam diabetes dari 30 responden, sebagian besar kadar gula darah tinggi yaitu sebanyak 21 responden $(70,0 \%)$ sedangkan kadar gula darah normal sebanyak 9 responden $(30,0 \%)$

Tingginya kadar gula pada penderita diabetes dikarenakan beberapa faktor seperti: Kebiasaan gaya hidup yang tidak sehat, misalnya merokok. Banyak mengkonsumsi makanan berlemak, sehingga menimbulkan kegemukan/ obesitas. Berkurangnya aktivitas fisik seperti olahraga yang membuat metabolisme dalam tubuh yang tidak sempurna sehingga tidak terkontrolnya kadar gula darah (Bagus, 2013 ).
\end{abstract}

Tabel 3 Distribusi Frekuensi Kadar Gula Darah Setelah Senam Diabetes di Klinik Symponi Danarieva Medika Palembang

\begin{tabular}{lcc}
\hline Kadar Gula Darah & $(\mathbf{n})$ & $\mathbf{( \% )}$ \\
\hline Normal $\quad(<200 \mathrm{mg} / \mathrm{dL})$ & 25 & $83,3 \%$ \\
Tinggi $\quad(>200 \mathrm{mg} / \mathrm{dL})$ & 5 & $16,7 \%$ \\
\hline Total & 30 & $100,0 \%$ \\
\hline
\end{tabular}

Sumber : Data primer, 2019

Berdasarkan data diatas didapatkan bahwa sebagian besar responden dengan kadar gula darah normal sebanyak 25 $(83,3 \%)$ dari 30 responden dengan ratarata kadar gula darah responden adalah 1,16 dengan standar deviasi 0,37 .

Pengaruh senam diabetes terhadap otototot akan berpengaruh terhadap penurunan kadar glukosa darah, dikarenakan reseptor insulin menjadi bertambah dengan bertambahnya otot tersebut, yang akirnya dapat meningkatkan sensitivitas insulin sehingga dapat meningkatkan keseimbangan glukosa, dengan cara molekul-molekul glukosa dapat dengan mudah melalui sel-sel otot (Hasdianah,2012).

\section{Analisis Bivariat}

Tabel 5. Pengaruh Senam Diabetes Terhadap Penurunan Kadar Gula Darah Pada Pasien Diabetes Mellitus Tipe II di Klinik Symponi Danarieva Medika Palembang

\begin{tabular}{lrrr}
\hline $\begin{array}{l}\text { Kadar Gula Darah } \\
\mathbf{N}\end{array}$ & Mean & Sd & p Value \\
\hline $\begin{array}{l}\text { Sebelum } \\
30\end{array}$ & 2.16 & 38.87 & 0.000 \\
Sesudah & 1.83 & 38.18 & \\
\hline
\end{tabular}

Sumber : Data primer, 2019

Berdasarkan data diatas didapatkan rata-rata kadar gula darah sebelum dilakukan senam diabetes adalah 2,16 dengan standar deviation 38,87 sedangkan kadar gula darah setelah dilakukan senam diabetes adalah 1,83 dengan standar deviation 38,18 . Dari nilai mean diketahui bahwa terdapat penurunan kadar gula darah sebesar 0,33. Dari hasil uji statistik didapatkan nilai $\rho$ value $=0.000<\alpha 0,05$. yang berarti ada pengaruh signifikan antara kadar gula darah sebelum dan setelah dilakukan senam diabetes.

Aktifitas fisik yang teratur dapat berperan dalam mencegah risiko DM dengan meningkatkan massa tubuh tanpa lemak dan secara bersamaan mengurangi lemak tubuh. Aktifitas fisik mengakibatkan insulin semakin meningkat sehingga kadar gula dalam darah akan berkurang. Orang yang jarang beraktifitas fisik dan jarang melakukan olahraga, zat makanan yang masuk ke dalam tubuh tidak akan dibakar tetapi akan ditimbun dalam bentuk lemak dan gula. Jika kondisi pankreas tidak adekuat dalam menghasilkan insulin dan tidak mencukupi untuk mengubah glukosa menjadi energi maka akan timbul penyakit DM (Kemenkes, 2010). 
Berdasarkan penelitian oleh Utomo, et al (2012) yang berjudul Pengaruh Senam Terhadap Kadar Gula Darah Penderita Diabetes pada 84 orang yang dibagi menjadi 2 kelompok, yakni kelompok intervensi dan tanpa intervensi. Pada kelompok intervensi dilakukan senam sebanyak 3 kali dalam seminggu. Penelitian tersebut menunjukkan bahwa terdapat perbedaaan kadar glukosa darah sewaktu sebelum dan sesudah pada kelompok dengan intervensi dengan penurunan glukosa darah 2,3 kali dibanding kelompok tanpa intervensi $(31,5$ $\mathrm{mg} / \mathrm{dl}$ berbanding $13,5 \mathrm{mg} / \mathrm{dl}$ ) dengan nilai $\mathrm{p}=0,0001$.

Hasil penelitian ini tidak sejalan dengan penelitian oleh Fahmi (2013) yang berjudul Pengaruh Senam Ergonomis pada Penderita DM Tipe 2 terhadap Kadar Glukosa Darah Puasa dan Kadar Glukosa 2 Jam Postprandial yang dilakukan pada 30 responden menemukan bahwa tidak terdapat perbedaan yang signifikan kadar glukosa darah puasa dan 2 jam postprandial pada kelompok intervensi dan kontrol dengan $\mathrm{p}=0,638$ dan $\mathrm{p}=0,877$ (Fahmi, 2013)

Berdasarkan hasil penelitian dan pembahasan diatas peneliti berpendapat bahwa senam diabetes merupakan salah satu aktifitas fisik yang sangat efektif jika dilakukan secara rutin. Olahraga aerobic yang mengikuti serangkaian gerak berurutan akan menguatkan dan mengembangkan otot dan semua bagian tubuh. Olahraga yang teratur akan lebih banyak memberi keuntungan, gula darah dan lemak darah terkontrol, peredaran darah lebih baik, tekanan darah stabil dan berat badan turun. Senam diabetes ini dilakukan sebanyak 3 kali dalam seminggu, namun masih terdapat banyak responden yang melakukan senam 1 hingga 2 kali dalam seminggu. Tidak patuhnya pelaksanaan senam diabetes ini berakibat tidak tercapainya efek senam yaitu penurunan glukosa darah puasa.

\section{KESIMPULAN}

Kadar Gula Darah pada pasien Diabetes Mellitus tipe II setelah mengikuti senam diabetes sebanyak 3x dalam seminggu di Klinik Symponi Danarieva Medika Palembang rata-rata normal yaitu kurang dari 200 mg/dL. Terdapat pengaruh yang signifikan senam diabetes terhadap penurunan kadar gula darah pada pasien Diabetes Mellitus tipe ii di Klinik Smponi Danarieva Medika Palembang.

\section{SARAN}

Diharapkan agar dapat meneliti variabel lain yang lebih bervariasi dan mencakup penelitian yang lebih luas dengan metode penelitian yang berbeda terutama yang berhubungan dengan kadar gula darah sebelum dan setelah dilakukan senam diabetes. Sehingga penelitian tentang kadar gula darah sebelum dan setelah dapat terus dikembangkan.

\section{DAFTAR PUSTAKA}

American Diabetes Association. 2014. Diagnosis and Classification of Diabetes Mellitus. Diabetes Care. 37(1): $\quad 81-90$ (http://care.diabetesjournals.org, diakses pada tanggal 22 Februari 2019 pukul 15:25 wib)

Agustina et al,.2016.Korelasi antara Kadar Albumin dan Lama PerawatanPasien Diabetes Melitus Tipe 2 dengan Kaki Diabetik di Departemen Penyakit Dalam RSMH Palembang

Dinas Kesehatan Kota Palembang 2018 
Erlina, Lina. 2008. Pengaruh Senam Diabetes Terhadap Kadar Glukosa Darah Pasien Dm Tipe 2 Di RSU Unit Swadana Daerah Kabupaten Sumedang

Fahmi. 2013. Pengaruh Senam Ergonomis pada Penderita DM Tipe 2 terhadap Kadar Glukosa Darah Puasa dan Kadar Glukosa 2 Jam Postprandial

Gondosari, Aleysius H. 2009. Karbohidrat Sederhana. (http://5Elemen.com. (Diakses 01 Mei 2019)).

Guelfi KJ, et all. 2007. Effect of Intermittent High-Intensity Compared with Continous Moderate Exercise on Glucose Production and Utilization in Individuals with Type I Diabetes. Am J Physiol Endocrinal Metabolism 292: E865-E870, 2007, diakses tanggal 8 Februari 2008.

Hidayat. 2017. Pengaruh Senam Terhadap Kadar Gula Darah Pada Penderita Diabetes Mellitus Tipe 2 Di RSUD Puri Husada Tembilahan Tahun 2016 Ilyas E.2007.Manfaat Latihan Jasmani Bagi Penyandang Diabetes Dalam Soegondo et al, Penatalaksanaan Diabetes Mellitus Terpadu. Jakarta: Balai Penerbit FKUI

Indriyani, P.S.H.S.A., (2007). Pengaruh Latihan Fisik; Senam Aerobik Terhadap Penurunan Kadar Gula Darah Pada Penderita Dm Tipe 2 Di Wilayah Puskesmas Bukateja Purbalingga. Media Ners, 1(2), pp. 49- 99.

Isnaini et al.2014.Faktor Resiko Yang Mempengaruhi Disbetes Mellitus Tipe II

Karinda, R. A. (2013). Pengaruh senam sehat diabetes mellitus terhadap profil lipid klien diabetes mellitus tipe 2 di wilayah kerja puskesmas patrang kabupaten jember. Skripsi Program Studi Ilmu Keperawatan, Universitas Jember, Jember
Noer, Sjaifoellah.1996.Buku Ajar Ilmu Penyakit Dalam Jilid 3.Jakarta: FKUI.

Notoatmodjo, Soekidjo. 2010. Metode penelitian kesehatan.Jakarta : PT Rineka Cipta

Notoatmodjo, Soekidjo. 2010. Metode penelitian kesehatan.Jakarta : PT Rineka Cipta

Nugraha et al,.2016.Kadar Gula Darah Sebelum dan Sesudah Melaksanakan Senam Diabetes pada Pasien Diabetes Melitus Tipe II

PERKENI. 2015. Revisi Final Konsesus DM Tipe 2 Indonesia. Konsensus Pengendalian dan Pencegahan Diabetes Mellitus Tipe 2 di Indonesia, Indonesia

(https://pbperkeni.or.id/wpcontent/uploads/201 9/01/4.-Konsensus-Pengelolaan-danPencegahan-Diabetes-melitus-tipe-2di-Indonesia-PERKENI-2015.pdf)

Powers, AC. 2008. Diabetes Mellitus. Harrison's Principles of Interne Medicine edition $17^{\text {th }}$ (halaman 2275-2304). The McGraw-Hill Companies, United State of America.

Rachmawati, et al. 2011. Pola Makan Dan Aktifitas Fisik Dengan Kadar Glukosa Darah Penderita Diabetes Mellitus Tipe 2 Rawat Jalan Di Rsup Dr. Wahidin Sudirohusodo Makassar

Rahim, et al. 2015. Pengaruh Senam Diabetes Terhadap Penurunan Kadar Gula Darah Pada Pasien Dengan Dm Tipe Ii Di Wilayah Kerja Puskesmas Global Kec. Limboto Kab. Gorontalo 